\title{
Mapping air temperature using time series analysis of LST: the SINTESI approach
}

\author{
S. M. Alfieri ${ }^{1}$, F. De Lorenzi ${ }^{1}$, and M. Menenti ${ }^{2}$ \\ ${ }^{1}$ National Research Council, Institute for the Agricultural and Forest System in the Mediterranean, Ercolano, Italy \\ ${ }^{2}$ Delft University of Technology, Department of Geoscience and Remote Sensing, Delft, the Netherlands
}

Correspondence to: S. M. Alfieri (silvia.alfieri@isafom.cnr.it)

Received: 28 September 2012 - Revised: 21 May 2013 - Accepted: 4 June 2013 - Published: 13 July 2013

\begin{abstract}
This paper presents a new procedure to map time series of air temperature $\left(T_{\mathrm{a}}\right)$ at fine spatial resolution using time series analysis of satellite-derived land surface temperature (LST) observations. The method assumes that air temperature is known at a single (reference) location such as in gridded climate data with grid size of the order of $35 \mathrm{~km} \times 35 \mathrm{~km}$. The LST spatial and temporal pattern within a grid cell has been modelled by the pixel-wise ratios $r(x, y, t)$ of the LST at any location to the LST at a reference location. A preliminary analysis of these patterns over a decade has demonstrated that their intra-annual variability is not negligible, with significant seasonality, even if it is stable throughout the years. The intra-annual variability has been modeled using Fourier series. We have evaluated the intra-annual variability by theoretically calculating the yearly evolution of LST $(t)$ for a range of cases as a function of terrain, land cover and hydrological conditions. These calculations are used to interpret the observed LST $(x, y, t)$ and $r(x, y, t)$. The inter-annual variability has been evaluated by modeling each year of observations using Fourier series and evaluating the interannual variability of Fourier coefficients. Because of the negligible interannual variability of $r(x, y, t)$, LST $(x, y, t)$ can be reconstructed in periods of time different from the ones when LST observations are available. Time series of $T_{\mathrm{a}}$ are generated using the ratio $r(x, y, t)$ and a linear regression between LST and $T_{\mathrm{a}}$. Such linear regression is applied in two ways: (a) to estimate LST at any time from observations or forecasts of $T_{\mathrm{a}}$ at the reference location; (b) to estimate $T_{\mathrm{a}}$ from LST at any location. The results presented in this paper are based on the analysis of daily MODIS LST observations over the period 2001-2010. The $T_{\mathrm{a}}$ at the reference location was gridded data at a node of a $35 \mathrm{~km} \times 35 \mathrm{~km}$ grid. Only one node was close to our study area and was used
\end{abstract}

for the work presented here. The regression of $T_{\mathrm{a}}$ on LST was determined using concurrent observations of $T_{\mathrm{a}}$ at the four available weather stations in the Valle Telesina (Italy), our study area.

The accuracy of our estimates is consistent with literature and with the combined accuracy of LST and $T_{\mathrm{a}}$. We obtained comparable error statistics when applying our method to LST data during periods different but adjacent to the periods used to model of $r(x, y, t)$. The method has also been evaluated against $T_{\mathrm{a}}$ observations for earlier periods of time (19841988), although available data are rather sparse in space and time. Slightly larger deviation were obtained. In all cases five days of averages from estimated and observed $T_{\mathrm{a}}$ were compared, giving a better accuracy.

\section{Introduction}

Air temperature $\left(T_{\mathrm{a}}\right)$ is an important variable in controlling land-atmosphere interaction and is a key input element for hydrology and land surface models. Modelling of crop growth and evapotranspiration requires climate data input. When dealing with studies of complex landscapes the knowledge of spatial fields of $T_{\mathrm{a}}$ is crucial. To give an example, differences of the order of 1 to $2 \mathrm{~K}$ in mean $T_{\mathrm{a}}$ may be determinant for the optimal growth of a certain crop (Vogt et al., 1997). In the case of complex terrains, local spatial variability of climate is not negligible and depends on several factors, among them topography, soil humidity and land use. As a consequence of spatial variability, local climatic conditions may or may not be suitable for the optimal growth of a specific crop. This leads to the need for detailed spatial patterns of $T_{\mathrm{a}}$. Insufficient attention, however, has been paid so far to 
the characterization of $T_{\mathrm{a}}$ fields within complex landscapes (Dobrowski et al., 2009).

$T_{\mathrm{a}}$ is observed at meteorological ground stations which provide data at specific locations. The sparse distribution of stations as well as the frequently insufficient temporal coverage severely constrain the study of climate-related processes in complex landscapes. Sparseness of stations and the frequent gaps in observations severely hamper the reconstruction of $T_{\mathrm{a}}$ spatial patterns by means of conventional interpolation techniques, e.g. inverse distance weighting or Kriging.

In contrast, large datasets on land surface temperature (LST) are actually available thanks to numerous Earth observation missions, e.g. the Moderate Resolution Imaging Spectroradiometer (MODIS), the Advanced Very High Resolution Radiometer (AVHRR), and the Advanced Along Track Scanning Radiometer (AATSR). These data are available at high temporal and spatial resolution over extended regions.

The impact of gaps in time series of LST satellite data can be mitigated by specific algorithms which identify and remove cloud-contaminated observations and fill the resulting gaps (Menenti et al., 1993; Gao et al., 2008).

Many authors estimated $T_{\mathrm{a}}$ using LST observations. In some studies the temperature-vegetation index method (TVX) has been used, based on the correlation between the vegetation index NDVI and LST (Prihodko and Goward, 1997; Nemani and Running, 1997; Stitsen et al., 2007; Nieto et al., 2011; Gallo et al., 2011). The TVX method is based on the assumption that LST is equal to $T_{\mathrm{a}}$ (with uniform atmospheric forcing and soil moisture conditions) when NDVI is higher than 0.65 (i.e. at full vegetation cover). Prihodko et al. (1997) estimated daily maximum $T_{\mathrm{a}}$ in Kansas with an absolute mean error (AME) of $3{ }^{\circ} \mathrm{C}$. Similar results were found in Oregon by Goward et al. (1994) (root mean square error RMSE $=5.4^{\circ} \mathrm{C}$ ), in Canada by Czajkowski et al. (1997) $\left(\mathrm{RMSE}=4.2^{\circ} \mathrm{C}\right)$, in Oklahoma by Czajkowski et al. (2000) $\left(\mathrm{RMSE}=2.08^{\circ} \mathrm{C}\right)$ and in Mediterranean climate by Nieto et al. (2011) (AME of $2.8^{\circ} \mathrm{C}$ and RMSE of $3.7^{\circ} \mathrm{C}$ ).

The limited applicability of this method to estimate maximum $T_{\mathrm{a}}$ was demonstrated by Vacutsem et al. (2010), who found a scarce correlation between $\left(\max T_{\mathrm{a}}-\mathrm{LST}\right)$ and NDVI. These authors estimated minimum $T_{\mathrm{a}}$ with RMSE varying between 2.86 and $3.02{ }^{\circ} \mathrm{C}$ and observed that the $T_{\mathrm{a}}$ estimated by the TVX method could be inaccurate or biased, depending on the study area.

Hengl et al. (2012) used MODIS LST images as an auxiliary predictor of $T_{\mathrm{a}}$. Temperature was modeled as a function of the MODIS LST as well as of latitude, longitude, distance from the sea, elevation, time and insolation. They obtained an average error of $\pm 2.4^{\circ} \mathrm{C}$ on $T_{\mathrm{a}}$.

The strong correlation between $T_{\mathrm{a}}$ and LST has been demonstrated in previous works (i.e. Kawashima et al., 2000; Jones et al., 2004; Park et al., 2005; Mostovoy et al., 2006). These authors used a linear regression between $T_{\mathrm{a}}$ and LST to increase spatial resolution of $T_{\mathrm{a}}$ fields. Kawashima et al. (2000) and Jones et al. (2004) observed a good correlation between LST observed by satellite and minimum $T_{\mathrm{a}}$ measured at different meteorological stations on specific winter days.

Mostovoy et al. (2006) estimated daily maximum and minimum $T_{\mathrm{a}}$ with linear regression on LST over the state of Mississippi for the period 2000-2004. They documented that the linear regression between LST and $T_{\mathrm{a}}$ resulted in very high correlation coefficients $R$. Furthermore the authors demonstrated that $R$ increases with decreasing pixel size of the LST image data and that $R$ depends on the season and land cover.

It is hard to assess the scale dependence of the $T_{\mathrm{a}}$ vs. LST regression, since adequate time series of LST are only available at a spatial resolution of $1 \mathrm{~km} \times 1 \mathrm{~km}$ or lower (imaging radiometers on-board geo-stationary satellites). At higher spatial resolution, the temporal sampling is not sufficient to determine the relationship between $T_{\mathrm{a}}$ and LST. For larger areas, spatially variable regression coefficients must be used as documented by the literature reviewed (e.g. Mostovoy et al., 2006; Shen and Leptoukh, 2011).

Shen and Leptoukh (2011) found that the AME of the estimated maximum $T_{\mathrm{a}}$ varies from $2.4^{\circ} \mathrm{C}$ over closed scrublands to $3.2^{\circ} \mathrm{C}$ over grasslands. AME of the estimated minimum $T_{\mathrm{a}}$ was about $3.0^{\circ} \mathrm{C}$. Maximum $T_{\mathrm{a}}$ was estimated by Younghui and Baiping (2012) in the Tibetan Plateau using linear regression of $T_{\mathrm{a}}$ on LST with a standard error between 2.25 and $3.23{ }^{\circ} \mathrm{C}$. Yan et al. (2009) performed validation of estimated $T_{\mathrm{a}}$ with measured $T_{\mathrm{a}}$ a using 335 synoptic weather stations in China for 2006 to show that the algorithm performs well with overall statistics of $R=0.96$ and RMSE $=3.23^{\circ} \mathrm{C}$. Xu et al. (2012) achieved an AME of $1.98^{\circ} \mathrm{C}$ and an $R^{2}=0.9215$.

The studies reviewed above are relatively few and they cover only limited periods of time ranging from several days to a season. No previous work is known to the authors on the determination of the relationship between LST and $T_{\mathrm{a}}$ over several years at daily temporal resolution, except a few cases e.g. Mostovoy et al. (2006). The review above demonstrates the increasing interest of the research community during the last decade in the use of satellite observed LST to estimate $T_{\mathrm{a}}$.

The relation between $T_{\mathrm{a}}$ and LST is especially strong during early afternoon hours when the radiative heating of the surface increases sensible heat flux under limited water availability (Oke, 1987). The latter led us to assume that observations of the spatial variability of maximum LST (in our case at the time of the daily overpass of TERRA/MODIS) could be used to characterize the spatial fields of maximum $T_{\mathrm{a}}$ over time. Increasing the temporal coverage of the analyzed LST images to several years could also help to identify any non-linearity in the relation between the spatial variation of radiative forcing and of LST. The latter is influenced by several land properties. Slope and elevation determine actual irradiance at a given location (Allen et al., 2006). In topographically complex areas, altitude as well as the structure of the boundary layer above the surface influence temperature, 
humidity and wind fields (Bertoldi et al., 2010). The partitioning of sensible and latent heat fluxes is influenced by the soil water content so that it has implicit control on LST $(\mathrm{Gu}$ et al., 2006; Mahmood et al., 2006). Further, vegetation indirectly influences LST changes by modulating the land surface response to weather and climate through turbulent transfer, transpiration and divergence of radiation.

The aim of this work was to develop a new procedure to retrieve spatial patterns of $T_{\mathrm{a}}$ over a certain area and period of time, starting from a very limited areal density of $T_{\mathrm{a}}$ data and from LST time series observed by satellite. Specifically, we want to estimate $T_{\mathrm{a}}$ at the spatial resolution of LST image data given $T_{\mathrm{a}}$ at a single reference location, e.g. at any node where gridded climate (either past or future) data are available (as explained in detail in Sect. 3).

To achieve this objective we need to characterize the spatio-temporal pattern of LST and to demonstrate the interannual stability of such pattern. This makes it possible to reconstruct the spatial patterns of $T_{\mathrm{a}}$ in different climate periods, particularly when no detailed spatial information is available (e.g. no satellite data available).

In synthesis we address the following questions: are spatial and temporal patterns of LST stable? Can we use time series of LST spatial data to capture and characterize such patterns? Can we characterize the coupling of near-surface $T_{\mathrm{a}}$ with LST using a limited areal density of meteorological stations?

The final result of this procedure should also be applicable, over a certain area, in time periods different from that analyzed, once the temporal stability of the LST spatial pattern has been demonstrated. This is the important innovation of our method compared with the ones generally used to retrieve $T_{\mathrm{a}}$ spatial patterns.

The Stable INvariant air and land surface TEmperature areal patterns by Fourier analySIs (SINTESI) approach will be described in detail in Sect. 2. Section 3 contains a brief description of the study area and of the data used in testing our method. Results from the spatio-temporal analysis of MODIS LST observations over the period 2001-2010 are presented in Sect. 4.1 while Sect. 4.2 describes the linear regression analysis performed to establish the $T_{\mathrm{a}}$ vs. LST relationship at the available ground stations. Comparison of $T_{\mathrm{a}}$ estimates with observations is discussed in Sect. 4.3. In Sect. 5.1 we compare the observed spatio-temporal patterns of LST with a theoretical calculation, taking into account the impact of terrain and land cover on solar irradiance and land surface energy budget. In Sect. 5.2 we evaluate our method against observations of $T_{\mathrm{a}}$ collected in the period of time preceding the launch of TERRA/MODIS.

\section{Methods}

\subsection{The SINTESI approach}

Our SINTESI approach is a procedure developed to map $T_{\mathrm{a}}$ at fine spatial resolution combining the LST observed by satellite and $T_{\mathrm{a}}$ data at a reference location. SINTESI is structured in several steps including preprocessing of the LST time series image data to identify missing data and outliers and to fill the resulting gaps. The procedure includes the following steps:

- normalization of spatial variability to a reference location, and construction of the time series of the ratio of LST $(x, y, t)$ to the LST at the reference location LST $\left(x_{0}, y_{0}, t\right)$, with $x$ and $y$ the coordinates, respectively, along the east and north and $t$ the time;

- modeling by Fourier series the ratio $\left[\operatorname{LST}(x, y, t) / \operatorname{LST}\left(x_{0}, y_{0}, t\right)\right]$ pixel-wise using multiannual observations by satellite thermal infrared measurements;

- evaluating the temporal stability of the Fourier coefficients;

- using mean values of the Fourier coefficients to obtain an estimated $\operatorname{LST}(x, y, t)$ at a given location as a function of LST $\left(x_{0}, y_{0}, t\right)$;

- determining the relationships between near-surface $T_{\mathrm{a}}$ and LST;

- combine the model of the time series of normalized LST with the regression $T_{\mathrm{a}}$ vs. LST to obtain $T_{\mathrm{a}}(x, y, t)$ as a function of LST $\left(x_{0}, y_{0}, t\right)$.

Figure 1 shows the work flow of the SINTESI procedure and the methodologies used to implement each steps. In the following paragraphs, a detailed description of each step is presented.

\subsection{Preprocessing of LST time series}

Satellite time series of optical data are often affected by cloud cover, haze or large viewing angles. The screening and removal of the contaminated observations as well as the temporal interpolation of the remaining observations to reconstruct gapless images has been performed by Harmonic ANalysis of Time Series (HANTS) algorithm (Menenti et al., 1993; Verhoef et al., 1996). The software was developed by The National Aerospace Laboratory of the Netherlands (NLR) institute and is freely available at the following internet site: http://gdsc.nlr.nl/gdsc/en/tools/hants.

Despite the fact that HANTS was designed specifically for the processing of NDVI images, it has been applied successfully to the LST time series (Julien et al., 2006). 


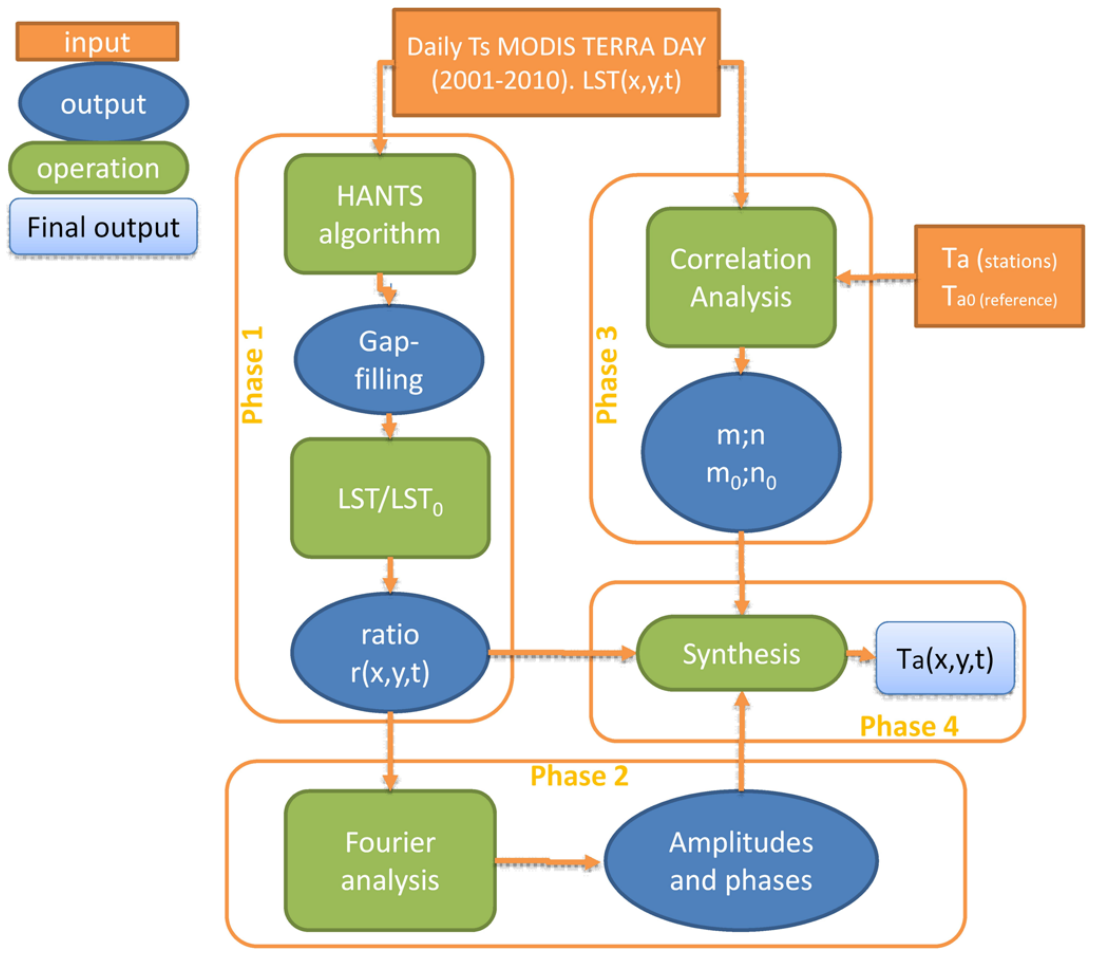

Fig. 1. Schematization of the SINTESI procedure.

The algorithm combines harmonic analysis with curve fitting in iterative steps. At each pixel, the signal is modelled using a Fourier series:

$y(t)=a_{0}+\left[\sum_{1}^{n_{\mathrm{f}}} a_{i} \cos \left(2 \pi f_{i} t_{y}\right)+b_{i} \sin \left(2 \pi f_{i} t_{y}\right)\right]$

where $n_{\mathrm{f}}$ is the number of frequencies, $a_{0}$ is the average of the series and $t_{y}$ the time of observation. The coefficients $a$ and $b$ are the coefficients of trigonometric components functions at the frequency $i$.

At each step the harmonic components are calculated on the data points after leaving out the outliers (i.e. cloudcontaminated observations). Outliers are identified at each step as observations deviating by more than a pre-defined threshold value (FET: the fit error tolerance) from the curve fitted at the previous step, and are weighted as zero in the subsequent curve-fitting iteration. The iterations continue until all the data in a time series are within the prescribed FET or when the number of data points is less than the minimum number of valid observations (DOD: degree of overdeterminedness). DOD and FET have to be specified by the user every time the HANTS algorithm is used. DOD must always be greater than or equal to the number of parameters that describe the curve but the user can decide to use more data points than the necessary minimum to improve the accuracy of the $a$ and $b$ coefficients.

The curve-fitting process is controlled, in addition to DOD and FET, by other three parameters as well (Roerink and
Menenti, 2000): the base period (BP), the number of frequencies (NOF) and Hi/Lo suppression lag (SF). BP indicates the number of time samples corresponding to the base frequency of the harmonic analysis. Also the time sampling of each observation is specified by the user in arbitrary units (in an input file listing the images to process). For example, the time unit is the hour the base period has been set to one day, i.e. $\mathrm{BP}=24$ units (hours in this example). The NOF is the number of frequencies to be used in the curve fitting and determines the degree of detail by which a curve/signal is described. Setting a low NOF produces a smooth curve with little details. A larger NOF leads to a less smooth curve with much more detail. SF indicates the direction of outliers with respect to the current curve. For example, clouds as well as mist or large view angle always have a negative effect (lower values) on LST so that the SF should always be set to "low". The same is for other variables, i.e. NDVI, while in other cases the direction could be positive due to higher values of the affected variable (e.g. cloud albedo) or more in general to errors caused by incorrect retrieval.

\subsection{Modelling the spatial patterns of LST}

The spatial pattern of LST is modeled by normalizing the pixel-wise LST time series at any location to the LST measured at the reference location $\left(x_{0}, y_{0}\right)$. The result is the 
pixel-wise ratio $r$ :

$r(x, y, t)=\frac{\operatorname{LST}(x, y, t)}{\operatorname{LST}\left(x_{0}, y_{0}, t\right) .}$

The choice of the reference location is arbitrary provided $r(x, y, t)$ is stationary and can be modeled by maps of the Fourier coefficients. The choice of the reference location changes the value of the ratio $r(x, y, t)$ but does not change the value of LST $(x, y, t)$.

The temporal stability of the pixel-wise ratio is evaluated using harmonic analysis. We used Fourier analysis to decompose the ratio $r(x, y, t)$ in three periodic signals with periods respectively 365,180 and 120 days. The $r$ time series are processed by a Fourier analysis on a yearly basis. For each frequency the amplitude and phase of the sine and cosine functions are determined. The inter-annual stability of the spatial pattern is evaluated on the basis of the inter-annual variability of the Fourier coefficients (amplitudes).

\subsection{Correlation analysis of $T_{\mathrm{a}}$ and LST}

We have established the relationship between the $T_{\mathrm{a}}$ measured at the available stations within our study area and LST by linear regression analysis:

$T_{\mathrm{a}}=\mathrm{LST} \cdot m_{i}+n_{i}$,

where subscript $i$ refers to a ground (meteorological) station. In this study we have used a single regression equation with coefficients $m$ and $n$ for the entire area, estimated by averaging $m_{i}$ and $n_{i}$. When aiming at the estimation of $T_{\mathrm{a}}$ over a period of time when no satellite observation of LST are available, the inverse regression is required at the reference location:

$\operatorname{LST}\left(x_{0}, y_{0}, t\right)=\frac{1}{m_{0}} \cdot T_{\mathrm{a}}\left(x_{0}, y_{0}, t\right)-n_{0}$,

where subscript ${ }_{0}$ indicates the reference location. The result of this analysis are the parameters $m, n, 1 / m_{0}$ and $-n_{0}$.

\section{$2.5 \quad T_{a}$ calculation}

Daily maximum $T_{\mathrm{a}}$ at each pixel location is estimated by

$$
\begin{aligned}
& T_{\mathrm{a}}(x, y, t)= \\
& \quad\left[\left(T_{\mathrm{a}}\left(x_{0}, y_{0}, t\right) \cdot 1 / m_{0}-n_{0}\right) \cdot r(x, y, t)\right] \cdot m+n,
\end{aligned}
$$

with $T_{\mathrm{a}}\left(x_{0}, y_{0}, t\right)$ the air temperature at the reference location.

The ratio $r$ is calculated as

$r(x, y, t)=a_{0}+\sum_{i=1}^{i=3} a_{i} \cos \left(2 \pi f_{i} t_{y}\right)+b_{i} \sin \left(2 \pi f_{i} t_{y}\right)$,

where

$a_{i}=\bar{A}_{i} \cdot \cos \left(\overline{\psi_{i}} \cdot \frac{\pi}{180}\right) ; b i=\bar{A}_{i} \cdot \sin \left(\bar{\psi}_{i} \cdot \frac{\pi}{180}\right)$

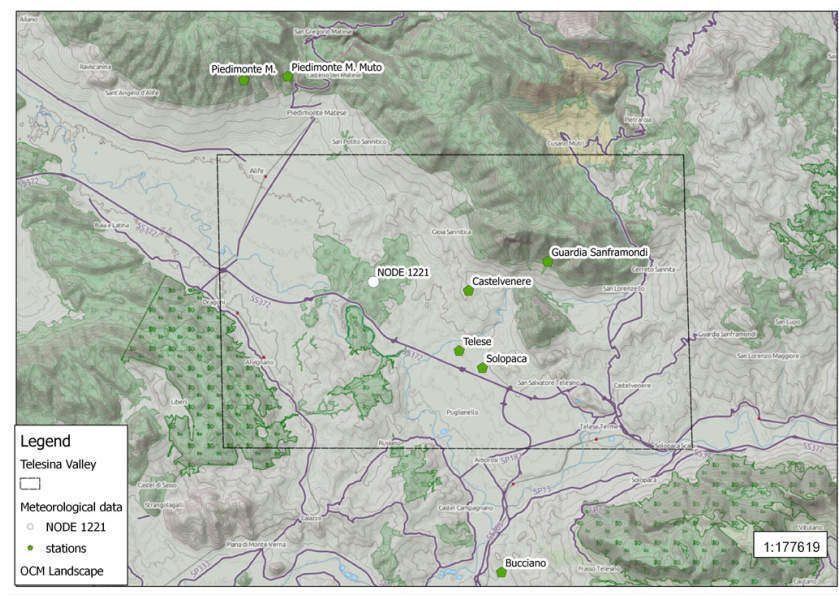

Fig. 2. Valle Telesina: location map showing the position of the node 1221 and of the ground meteorological stations.

with $\bar{A}_{i}$ and $\overline{\psi_{i}}$ being, respectively, the amplitude and phase of the $i$-th harmonic component averaged over the years, spanning the analyzed LST time series once the interannual stability of the ratio $r$ has been verified.

\section{Materials}

We implemented and evaluated the SINTESI algorithm on data collected in the Valle Telesina area (Southern Italy) to obtain temporal maps of daily maximum $T_{\mathrm{a}}$ at $1 \mathrm{~km} \times 1 \mathrm{~km}$ resolution. We used three datasets:

- we have constructed the model $r(x, y, t)$ using TERRA/MODIS LST data, spanning the period between 1 January 2001 to 31 December 2010;

- we used as $T_{\mathrm{a}}$ at the reference location $\left(x_{0}, y_{0}\right)$ the $T_{\mathrm{a}}$ available at node 1221 of a gridded dataset available on the entire Italian territory at $35 \mathrm{~km} \times 35 \mathrm{~km}$ resolution. This dataset is available from 1950 onward (Esposito, 2010). Further, scenarios on future climate have been generated for the same grid (Tomozeiu et al., 2007), produced within the Italian project "Agroscenari" (Fig. 2);

- to establish the relationship between $T_{\mathrm{a}}$ and LST we have used the observations of $T_{\mathrm{a}}$ at four ground stations within the $35 \mathrm{~km} \times 35 \mathrm{~km}$ grid spanning the period between 2001 and 2010 (Fig. 2).

\subsection{Study area}

The Valle Telesina area is a 20000 ha complex landscape located in the west-central area of the Benevento province (Campania region, Southern Italy). The dominant morphological structure is a graben, where the Calore river flows. It is bounded on the north by the calcareous horst of MateseMonte Maggiore and on the south by the mountain group 
Table 1. Meteorological ground stations in the study area and belonging to the Rete Agrometeorologica Regionale (Campania Region).

\begin{tabular}{lrrr}
\hline Station & $\begin{array}{r}\text { Latitude } \\
\mathrm{N}\left(^{\circ}\right)\end{array}$ & $\begin{array}{r}\text { Longitude } \\
\mathrm{E}\left(^{\circ}\right)\end{array}$ & $\begin{array}{r}\text { Altitude } \\
\left({ }^{\circ}\right)\end{array}$ \\
\hline Telese & 41.20 & 14.53 & $66 \mathrm{~m}$ \\
Castelvenere & 41.23 & 14.54 & $125 \mathrm{~m}$ \\
Guardia Sanframondi & 41.25 & 14.60 & $335 \mathrm{~m}$ \\
Solopaca & 41.19 & 14.55 & $220 \mathrm{~m}$ \\
\hline
\end{tabular}

of Taburno Camposauro. The latter extend from north-east (Croce, Ciesco and Montesella mountains) to north-west (Monaco di Gioia mountain). Because of the complex morphological setting, the elevation over the area spans a wide range. The leading high ground is the Camposauro mountain (1349 ma.s.1.). The minimum altitude is found at the confluence of the Calore with Volturno river ( $34 \mathrm{~m}$ a.s.1.). Mean annual rainfall over the area is about $1000 \mathrm{~mm}$ and spatial variability over the area is significant. About $70 \%$ of the total precipitation is concentrated between autumn and winter while the summer is almost dry. Annual mean temperature is about $15.9^{\circ} \mathrm{C}$.

\subsection{Data}

\subsubsection{MODIS data}

Daily LST time series acquired between 1 January 2001 and 31 December 2010 by MODIS on the Terra satellite (MOD11A1 product) were used in our analysis, after downloading from the NASA ftp server (ftp://e4ft101.cr.usgs. gov). We processed the latest product level MOD11A1-V05, whose accuracy and stability of data are significantly improved compared to the previous versions (Wan et al., 2008). The most important refinement with respect to the version 04 consists in keeping to a minimum any cloud-contaminated LST observations while maintaining a good level of accuracy.

The V5 MOD11A1 products are projected in a Sinusoidal grid by mapping the level-2 LST product (MOD11_L2) on a $0.928 \mathrm{~km} \times 0.928 \mathrm{~km}$ grid. This product contains LST as well as band 31 and 32 emissivity $(\varepsilon)$, clear sky coverage, quality control assessment, view zenith angle and time of observation.

The LST retrieval is based on the split-window method (Wan and Dozier, 1996). In this approach, the surface $\varepsilon$ in band 31 and 32 are supposed to be known on the basis of the land cover type (MOD12C1). The accuracy of LST retrieval depends on the $\varepsilon$ values set in the two split-window channels. In the case of high heterogeneity over the pixel, errors might occur in specifying $\varepsilon$ from land cover type, especially in arid and semi-arid areas, where overestimates of $\varepsilon$ are often observed (Wan et al., 2004). Also, the variation of $\varepsilon$ with the
Table 2. HANTS parameter settings used in this study.

\begin{tabular}{ll}
\hline Parameter & Value \\
\hline Valid range (VR) & $250-350 \mathrm{~K}$ \\
Outliers direction (OD) & "Low" \\
Fit error tolerance (FET) & $5 \mathrm{~K}$ \\
Degree of overdeterminedness (DOD) & 50 \\
Number of frequencies (NOF) & 3 \\
Base period (BP) & 365 \\
\hline
\end{tabular}

instrument view angle might cause additional uncertainties. The LST accuracy is better than $1 \mathrm{~K}$ over heterogeneous surfaces, as demonstrated in field experiments over water, crop and grassland. On the other hand, the uncertainty in land surface temperature can be very large if the measurements are affected by clouds or heavy aerosol.

In this work we aim to determine the maximum daily value of land surface temperature and therefore used LST observations at the daily overpass of the Terra satellite.

Time of LST data sampling is about 11:30 Local Solar Time, which is close to the time of maximum $T_{\mathrm{a}}$. Moreover, Mostovoy et al. (2006) showed that the effect of the difference between the satellite overpass time and the time when maximum $T_{\mathrm{a}}$ is observed at ground station does not alter the correlation coefficients of the linear regression of $T_{\mathrm{a}}$ vs. LST. This result suggests that the difference in MODIS overpass time with respect to the time of maximum $T_{\mathrm{a}}$ observations does not produce significant errors in estimating maximum air temperature.

\subsubsection{Meteorological data}

We have used two sets of meteorological data:

a. Meteorological measurements at the ground stations (Fig. 2) have been provided by the Regional Agrometeorological network of the Campania region. Table 1 lists the stations and data available in the period 2001-2010 over Valle Telesina.

b. $T_{\text {a }}$ gridded data at the reference location (Fig. 2) has been produced within the project Agroscenari, applying kriging with an external drift method (Wackernagel, 1998; Hengl et al., 2003) to the meteorological data included in the National Agro-metereological database (Ministry of Agriculture, Food and Forestry Policies, 1990). Daily meteorological data have been gridded at $35 \mathrm{~km} \times 35 \mathrm{~km}$ resolution for the period from 1950 onwards (Esposito, 2010). This gridded dataset is the reference data on Italian climate and climate scenarios are constructed using the same grid. Our method downscales these gridded data on $T_{\mathrm{a}}$ to a finer $1 \mathrm{~km} \times 1 \mathrm{~km}$ grid. 


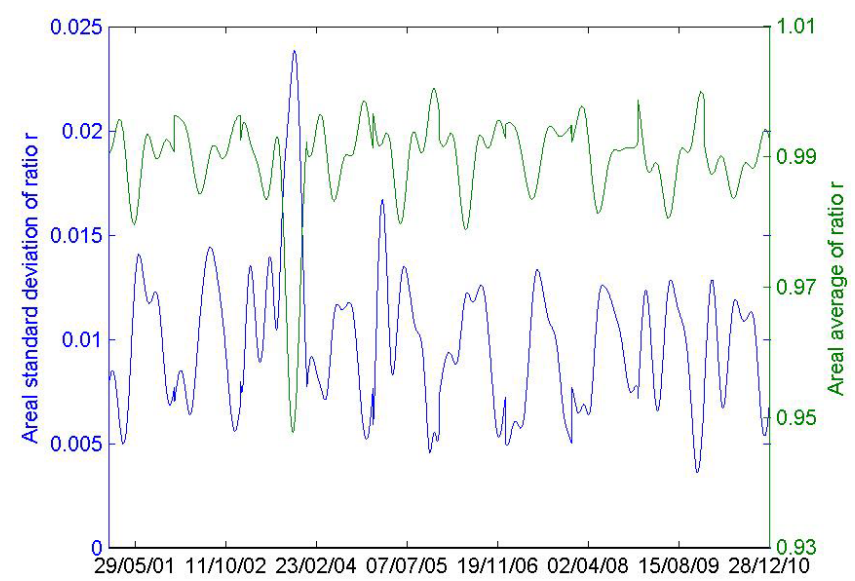

Fig. 3. Daily trend of areal average (green line) and areal standard deviation (blue line) of $r$ ratio from 2001 to 2010.

\section{Results}

\subsection{Spatio-temporal variation of LST}

LST image data were processed using the HANTS algorithm to remove invalid observations and to fill the resulting gaps in the time series (Menenti et al., 1993, 2010). HANTS identifies and removes cloud-affected observations in all the pixels of all images in the time series and fills the resulting gaps using Fourier series to model the time series. The application of HANTS required a preliminary analysis of the data to identify the best set of input parameters. In Table 2 the input parameters values that we set in our analysis are listed.

The target error (FET) and the number of frequencies are the main parameters playing a role in the successful application of the HANTS algorithm. We evaluated the reconstruction with FET $=3,5$ and $8 \mathrm{~K}$ and concluded that cloudaffected observations were assessed as valid when using $\mathrm{FET}=3$ and $\mathrm{FET}=8$. We therefore decided to use $\mathrm{FET}=5$. This FET value was also suggested by Julien et al. (2006) for cloud removal in the LST time series.

We evaluated different options to choose the NOF parameter, concluding that a more realistic reconstruction of LST time series is obtained using three frequencies. An increasing number of frequencies yields artefacts in the reconstructed time series, e.g. a sharp increase or decrease of LST over a short period of time. These are especially evident when gaps are present in combination with inaccurate measurements (Alfieri et al., 2012). Therefore, a value of 3 was set for NOF, i.e. we used three frequencies with periods 365,180 and 120 days.

The spatial pattern of LST on any given day was characterized by the ratio $r$ of the LST image to the LST at the position of the node 1221, using reconstructed surface temperature values. The ratio $r$ showed a periodical trend, reflecting the seasonality of the factors involved in the surface energy balance (see green line in Fig. 3). The lower $r$ values during the winter season are the combination of two effects. The higher precipitation in winter affects soil humidity over the area, thus changing the energy partitioning between latent and heat fluxes. In addition, the seasonality of solar radiation (lower values in winter) also causes LST ratios to be lower in winter than in summer. The amount of solar radiation received by a certain surface is in fact controlled by the relative position of the sun as well as by the local orientation of the land surface.

The lower radiative forcing in winter is also evident in the smaller spatial variability of $r$ than during the summer (Fig. 4). LST spatial variability on local scale depends on factors primarily linked to local morphology like slope, aspect and elevation. They have a direct influence on the amount of radiation received by the surface. In addition, soil use and soil water content also have a significant role in energy partitioning, and therefore on LST. The spatial pattern of $r$ is related to the combination of all these factors. The matter will be discussed more in detail in Sect. 5.1.

A first evaluation of the area-averaged ratio $r$ shown in Fig. 3 points out that, although the intra-annual variability is significant, it seems to be stable through the decade 20012010. The exception is the year 2003 where a sharp decrease of mean $r$ is observed around the end of summer. Areal standard deviation of the ratio $r$ shows the same trend, suggesting that the spatial pattern of the ratio is also quite stable in time (blue line in Fig. 3) with the exception of 2003. Standard deviation values vary between 0.005 and 0.016 , depending on the season with exception of the maximum value during the summer of 2003 (0.024).

Intra-annual variability cannot be neglected although its inter-annual trend seems to be stable. The observed yearly mean seasonal patterns provide further support to this statement. Here we only show the summer and winter patterns of a representative year (2007) compared with the anomalous year 2003 (Fig. 4). Summer and winter spatial fields of the ratio $r$ calculated over the remaining years presents similar patterns.

We applied harmonic analysis to each year separately in order to obtain a quantitative estimation of the inter-annual variability of the yearly, half-yearly and seasonal periodic components of the $r$ signal. The inter-annual variability of the pixel-wise ratio $r$ has been evaluated by statistics of the yearly mean value $A_{0}$ and of the amplitudes $A_{1}, A_{2}, A_{3}$ of components with periods of 365,180 and 120 days obtained by Fourier analysis (Table 3 ). We then evaluated the contributions $\delta r_{i}$ to the total error on $r(x, y, t)$ due to assuming constant values of $A_{0}, A_{1}, A_{2}$ and $A_{3}$. We took $\delta r_{0}=\sigma_{A 0} / A_{0}$ and $\delta r_{i}=\sigma_{A i} /\left(\bar{A}_{0}+\bar{A}_{i}\right)\left(A_{0}\right.$ is the yearly average of $r$ and $A_{i}$ is the amplitude of the $i$-th component of the Fourier series with $i \neq 0$ ). This gives an estimation of the contribution to the total relative error we introduced when assuming interannual stability of the ratio $r$, i.e. assuming constant values of $A_{0}, A_{1}, A_{2}$ and $A_{3}$. 

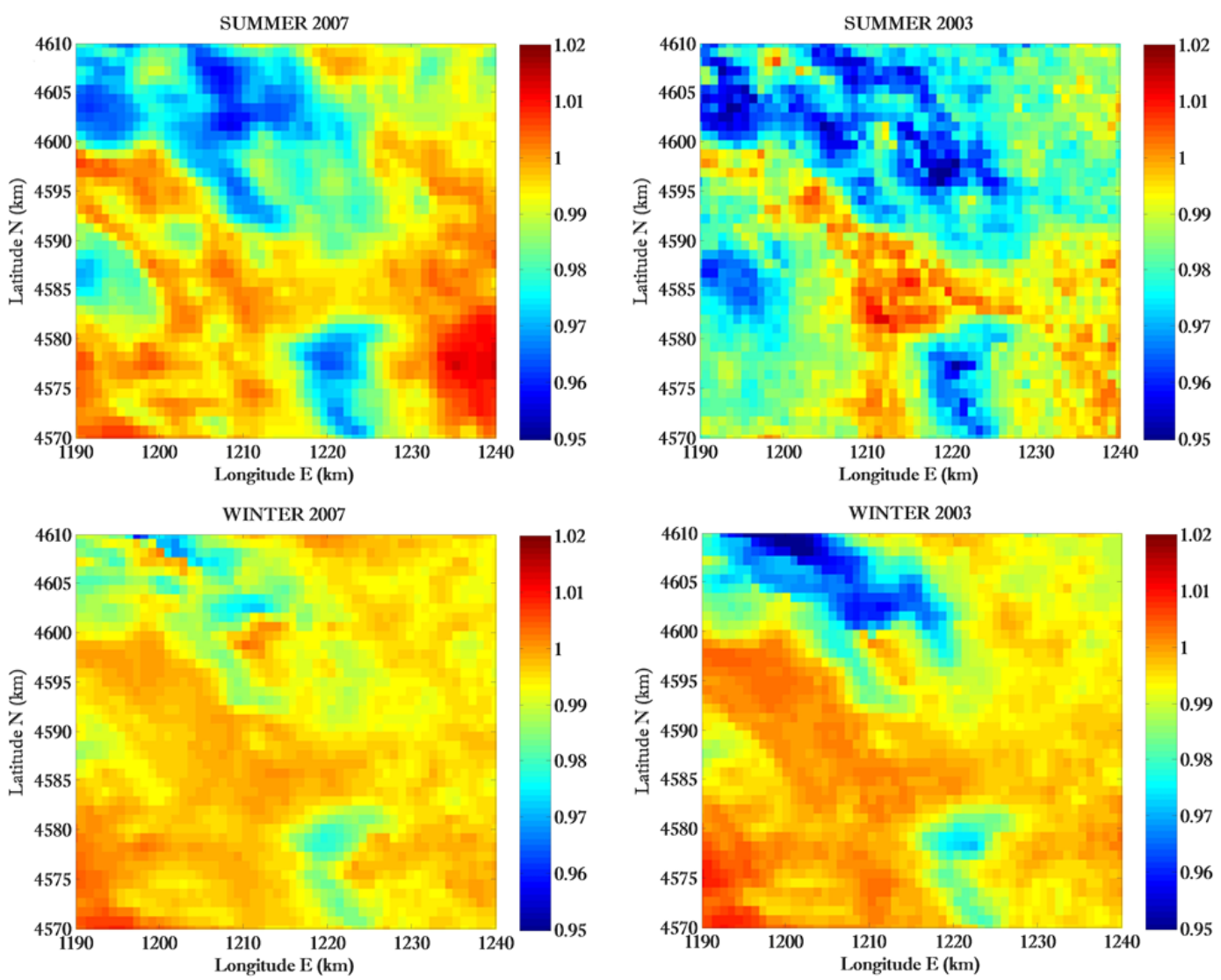

Fig. 4. Spatial pattern of the winter and summer average of the daily ratio $r$ in 2003 and 2007.
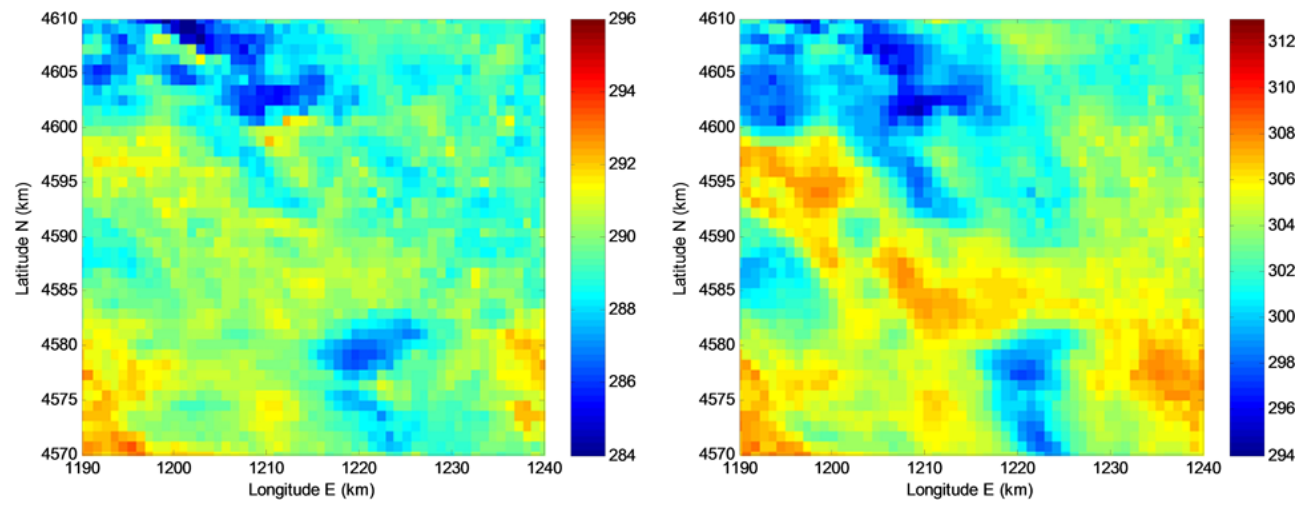

Fig. 5. Estimated $T_{\mathrm{a}}$ on 1 January 2006 (left) and on 1 July 2006 (right).

Table 3 shows area average values of $A_{0}, A_{1}, A_{2}, A_{3}$ for each year from 2001 to 2010. Anomalous behavior of 2003 year is also evident in the values of the amplitudes we obtained. The total relative error has been calculated as $\delta r=$ $\sum_{i=0}^{i=3} \delta r_{i}$ using the statistics over the period 2001-2010 and then over the same period but leaving out 2003. In the former case we obtained $\delta r=1.1 \%$ and in the latter $\delta r=0.3 \%$. On the basis of these findings we considered negligible the inter-annual variability of the annual evolution of the ratio $r$. Then we can construct a yearly time series of the ratio $r$, describing the spatial and intra-annual variability in any period of time, using the mean values of $r$ and of the harmonic components over the period from 2001 to 2010. 
Table 3. Yearly area-averaged mean ratio $\mathrm{r}$ and amplitudes derived by Fourier analysis (values multiplied by $10^{2}$ ).

\begin{tabular}{|c|c|c|c|c|c|c|c|c|c|}
\hline \multirow[b]{2}{*}{ Year } & \multirow[b]{2}{*}{$A_{0}$} & \multicolumn{3}{|c|}{ Period in days } & \multicolumn{5}{|c|}{ Period in days } \\
\hline & & $365\left(A_{1}\right)$ & $180\left(A_{2}\right)$ & $120\left(A_{3}\right)$ & Year & $A_{0}$ & $365\left(A_{1}\right)$ & $180\left(A_{2}\right)$ & $120\left(A_{3}\right)$ \\
\hline 2001 & 99.0 & 0.6 & 0.5 & 0.4 & 2006 & 99.0 & 0.7 & 0.4 & 0.3 \\
\hline 2002 & 99.1 & 0.6 & 0.4 & 0.2 & 2007 & 99.1 & 0.6 & 0.4 & 0.2 \\
\hline 2003 & 98.1 & 1.7 & 1.5 & 0.7 & 2008 & 99.0 & 0.6 & 0.5 & 0.3 \\
\hline 2004 & 99.2 & 0.6 & 0.3 & 0.4 & 2009 & 99.0 & 0.7 & 0.3 & 0.4 \\
\hline 2005 & 99.1 & 0.8 & 0.4 & 0.5 & 2010 & 98.9 & 0.4 & 0.3 & 0.3 \\
\hline
\end{tabular}

\subsection{Relationship air temperature vs. surface temperature}

The relationship between $T_{\mathrm{a}}$ data at the stations within the Valle Telesina area (Table 1 and Fig. 2) and LST MODIS observations has been determined by linear regression analysis. Daily values of maximum $T_{\mathrm{a}}$ and daytime MODIS LST were correlated for each year from 2001 to 2010.

Linear regression coefficients (slope $m$ and offset $n$ ) as well as $R^{2}$ were calculated for each of the available stations and for each year. The same statistics were produced by determining a single relationship for the whole area (using data from all the stations). Table 5 shows the mean and the standard deviation of the $m, n$ and $R^{2}$ over the entire period (2001-2010). The coefficients $R^{2}$ are always greater than 0.83 . The correlation coefficients do not vary significantly across the stations. The largest variation has been observed at Guardia Sanframondi that is located at an higher altitude than the other stations. Considering these results, as well as the impossibility to define a detailed spatial pattern of regression coefficients (because of the scarce availability of ground stations), we decided to use a single relationship valid for the whole area under study. This conclusion is based on the comparison of estimates of $T_{\mathrm{a}}$ obtained with the station-specific relationship with the estimates obtained with the relationship applicable to the entire area. The difference between the two $T_{\mathrm{a}}$ estimations was rather small as shown by the RMSE and AME statistics (Table 6). The RMSE increment, using the same linear regression all over the area, is between 1.24 and $3.92 \%$, while the AME increment vary between 1.24 and $6.45 \%$ (Table 6).

The inverse relationship (LST vs. $T_{\mathrm{a}}$ ) was evaluated at the reference location giving the regression coefficients $1 / m_{0}=$ 0.87 and $-n_{0}=38.81$.

\subsection{Time series of daily air temperature maps}

The annual evolution of the ratio $r$ was modelled with a Fourier series using amplitude and phase of the three terms in the series averaged over the period 2001-2010. Time series of $T_{\mathrm{a}}$ maps were calculated over Valle Telesina for the period from 2001 to 2010 using the ratio $r(x, y, t)$. Figure 5 shows

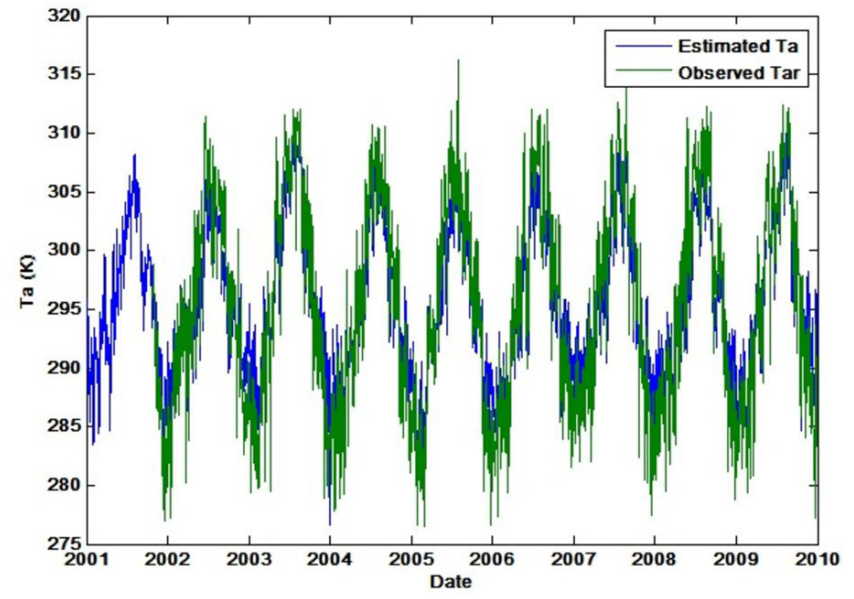

Fig. 6. Daily values of estimated against observed $T_{\mathrm{a}}$ at Guardia Sanframondi station (2001-2010).

the estimated $T_{\mathrm{a}}$ on 1 January and on 1 July 2006: the range of variability over the area is $14 \mathrm{~K}$, respectively $20 \mathrm{~K}$.

We then evaluated the $T_{\mathrm{a}}(x, y, t)$ estimates (Table 7) against available observations in the same period. We calculated the following statistics: RMSE, AME, mean and standard deviation of the differences between estimated and measured $T_{\mathrm{a}}$ (MR and STDR) and $R^{2}$.

RMSE values vary in a range between $2.47 \mathrm{~K}$ and $3.23 \mathrm{~K}$. We observed a strong correlation of our estimates with observed maximum temperatures $\left(R^{2}>r 0.90\right)$. MR values indicate that $T_{\mathrm{a}}$ estimates at Solopaca and Guardia Sanframondi are on average close to the observed $T_{\mathrm{a}}$ (Fig. 6 shows the temporal trend of observed against estimated $T_{\mathrm{a}}$ at Guardia Sanframondi station).

\section{Discussion}

\subsection{Land surface processes determining the spatio-temporal variation of LST}

Several factors determine the LST variation in space and time and the coupling between $T_{\mathrm{a}}$ and LST. Solar irradiance forces the surface energy balance, and the residual heat 
Table 4. Comparison of the statistics (mean $\left(\bar{A}_{i}\right)$, standard deviation $(\sigma)$ and coefficient of variation $\left.\delta r_{i}\right)$ of the mean ratio $r$ and harmonic amplitudes calculated over the period 2001-2010.

\begin{tabular}{|c|c|c|c|c|c|c|c|c|}
\hline & \multicolumn{4}{|c|}{ Statistics over 2001-2010 } & \multicolumn{4}{|c|}{ Statistics leaving out 2003} \\
\hline & \multicolumn{4}{|c|}{ Period in days } & \multicolumn{3}{|c|}{ Period in days } & \multirow[b]{2}{*}{$120\left(A_{3}\right)$} \\
\hline & $A_{0}$ & $365\left(A_{1}\right)$ & $180\left(A_{2}\right)$ & $120\left(A_{3}\right)$ & $A_{0}$ & $365\left(A_{1}\right)$ & $180\left(A_{2}\right)$ & \\
\hline $\bar{A}_{i}\left(\times 10^{2}\right)$ & 98.96 & 0.72 & 0.49 & 0.36 & 99.06 & 0.62 & 0.37 & 0.32 \\
\hline$\sigma\left(\times 10^{2}\right)$ & 0.31 & 0.32 & 0.35 & 0.14 & 0.09 & 0.10 & 0.07 & 0.09 \\
\hline$\delta r_{i}(\%)$ & 0.31 & 0.32 & 0.35 & 0.14 & 0.10 & 0.10 & 0.07 & 0.09 \\
\hline
\end{tabular}

Table 5. Statistics over the period 2001-2010 of the linear regression parameters and correlation coefficient $R^{2}$ calculated at the available stations in Valle Telesina.

\begin{tabular}{lrrr}
\hline & $m_{1}($ mean $\pm \mathrm{std})$ & $n_{1}($ mean $\pm \mathrm{std})$ & $R^{2}$ (mean $\left.\pm \mathrm{std}\right)$ \\
\hline Solopaca & $0.78 \pm 0.04$ & $67.17 \pm 11.64$ & $0.84 \pm 0.05$ \\
Castelvenere & $0.82 \pm 0.03$ & $53.93 \pm 8.24$ & $0.84 \pm 0.03$ \\
Guardia Sanframondi & $0.88 \pm 0.02$ & $38.05 \pm 6.66$ & $0.87 \pm 0.03$ \\
Telese & $0.79 \pm 0.04$ & $62.83 \pm 11.37$ & $0.84 \pm 0.05$ \\
All stations & $0.81 \pm 0.01$ & $59.41 \pm 4.02$ & $0.83 \pm 0.00$ \\
\hline
\end{tabular}

forces the soil heat balance and surface temperature, which in turn forces air temperature. Solar irradiance on a tilted surface depends on date and latitude as well as slope and exposure angles. Then, over complex landscapes, morphology is crucial in determining the LST pattern. Other factors act to reduce surface temperature by decreasing the residual soil heat flux at given irradiance. Land cover and soil water content play such a role in determining soil heat flux and surface temperature.

To illustrate the combined effect of such factors on LST and to evaluate whether our $r(x, y, t)$ can be explained by these processes, we constructed a number of synthetic time series of LST for a range of terrain and land cover conditions. The daily amplitude of a periodic oscillation of LST can be described by its explicit relationship with heat flux into the soil $G\left(\mathrm{~W} \mathrm{~m}^{-2}\right)$ and thermal admittance $Y\left(\mathrm{~W} \mathrm{~m}^{-2} \mathrm{~K}^{-1}\right)$ (Menenti, 1984):

$$
\begin{array}{r}
A(\mathrm{LST})=A(G) / Y, \\
\text { where } \\
Y=\sqrt{2 \cdot \pi \cdot \lambda \cdot \rho \cdot c / P}
\end{array}
$$

with $\lambda$ being the thermal conductivity $\left(\mathrm{W} \mathrm{m}^{-1} \mathrm{~K}^{-1}\right), \rho$ the soil density $\left(\mathrm{kg} \mathrm{cm}^{-1}\right), c$ the specific heat $\left(\mathrm{J} \mathrm{kg} \mathrm{K}^{-1}\right)$ and $P$ is the period (s).

The ratio of soil heat flux to net radiation $G / R_{n}\left(\mathrm{~W} \mathrm{~m}^{-2}\right)$ is approximately related to land cover type (Kustas et al., $1993)$, so that $A(G)$ can be easily estimated from the daily amplitude of net radiation $A\left(R_{n}\right)$ :

$A(G)=\left(G / R_{n}\right) \cdot A\left(R_{n}\right)$.
Net radiation $\left(\mathrm{W} \mathrm{m}^{-2}\right)$ can be calculated in a simplified way by neglecting the longwave net radiation

$R_{n}=(1-\alpha) \cdot R_{\mathrm{glob}} \cdot \cos (i)$.

$R_{\text {glob }}$ is the mean daily solar irradiance over the day, $\alpha$ the albedo and $i$ the incidence angle of the sun $(\pi)$. The latter is

$\cos (i)=\cos \phi_{\mathrm{s}} \cdot \cos \phi_{\mathrm{a}}+\sin \phi_{\mathrm{s}} \cdot \sin \alpha \cdot \cos \left(\phi_{\mathrm{s}}-\phi_{n},\right)$

where $\phi_{\mathrm{a}}$ is the slope angle, $\phi_{\mathrm{s}}$ the solar azimuth angle and $\phi_{n}$ the slope aspect angle.

Replacing Eqs. (9) and (10) into Eq. (8) we obtain the amplitude of LST (K) over the period (day). Daily maximum LST is given by

$\operatorname{LST}(t)=\operatorname{LST}_{m}(t)+A(\mathrm{LST}$,

where $\operatorname{LST}_{m}(t)$ is the daily mean LST which we took equal for all cases. We calculated 24 sets of the annual evolution of daily LST over the year 2006 (as an example) combining the parameters values in Table 8 with actual measurements of $R_{\text {glob. }}$. The lowest values of LST are given by the combination of parameters corresponding to a forested area, wet soil, northern exposure and 0.35 rad slope angle (case B in Fig. 7). Instead the highest values correspond to a dry area, bare soil, southern exposure and 0.35 rad slope (case A in Fig. 7).

We can now use the theoretical calculation described above to interpret the observed $r(x, y, t)$ patterns derived from the analysis of MODIS LST time series.

Let's now take as reference the case with the highest daily LST in summer (case A in Fig. 7). Then let us take the case with the lowest daily LST in summer (case B in Fig. 7) and a 
Table 6. RMSE and AME errors and their relative increment of $T_{\mathrm{a}}$ estimation (2001-2010) using station-specific linear regressions respectively a single linear regression.

\begin{tabular}{lrrrrrrrrr}
\hline & \multicolumn{2}{c}{ Station specific } & & \multicolumn{2}{c}{ All station } & & \multicolumn{2}{c}{ Increment of error \% } \\
\cline { 2 - 3 } & RMSE & AME & & RMSE & AME & & RMSE & AME \\
\hline Solopaca & 3.37 & 2.64 & & 3.51 & 2.78 & & 3.92 & 5.40 \\
Castelvenere & 3.45 & 2.71 & & 3.63 & 2.85 & & 5.28 & 5.24 \\
Guardia Sanframondi & 3.38 & 2.63 & & 3.59 & 2.80 & & 6.43 & 6.45 \\
Telese & 3.28 & 2.58 & & 3.32 & 2.61 & & 1.24 & 1.24 \\
\hline
\end{tabular}

Table 7. Error statistics of $T_{\mathrm{a}}$ estimates against observations at the available stations.

\begin{tabular}{lrrrrr}
\hline & \multicolumn{5}{c}{ Validation 2001-2010 } \\
\hline & RMSE & AME & MR & STDR & $R^{2}$ \\
\hline Castelvenere & 3.23 & 2.70 & 2.21 & 2.37 & 0.95 \\
Telese & 2.47 & 1.91 & 0.99 & 2.26 & 0.95 \\
Guardia Sanframondi & 3.12 & 2.58 & -0.15 & 3.12 & 0.92 \\
Solopaca & 2.63 & 1.99 & -0.26 & 2.62 & 0.94 \\
\hline
\end{tabular}

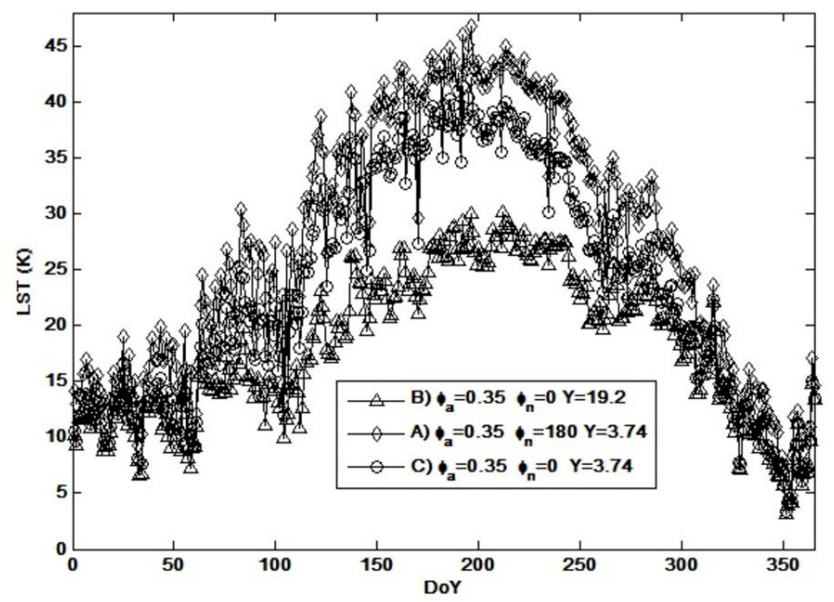

Fig. 7. Maximum (black diamonds; case A), minimum (black triangles; case B) and an arbitrary case (black circles; case C) selected out of the 24 yearly time series of LST estimated by Eqs. (8)-(13) applying the parameters in Table 8 .

third arbitrary case (case $\mathrm{C}$ in Fig. 7). Case $\mathrm{C}$ applies to dry bare soil facing south with a 0.35 rad slope angle. Radiative forcing $(\mathrm{Rn})$ is smallest for case B because it is north-facing and the combination of albedo and the ratio $G / \mathrm{Rn}$. Moreover, the thermal admittance $(Y)$ is very large because of the wet soil. The combination of low Rn and large $Y$ gives a small daily amplitude of LST. Conversely, radiative forcing is largest for the south facing case B with small $Y$ because of the dry soil. This gives a large daily amplitude of LST.

If we now calculate the ratio $r(t)$ of case $\mathrm{C}$ to case $\mathrm{A}$ we obtain the $r(t)$ "case warm" in Fig. 8. Conversely, if we take

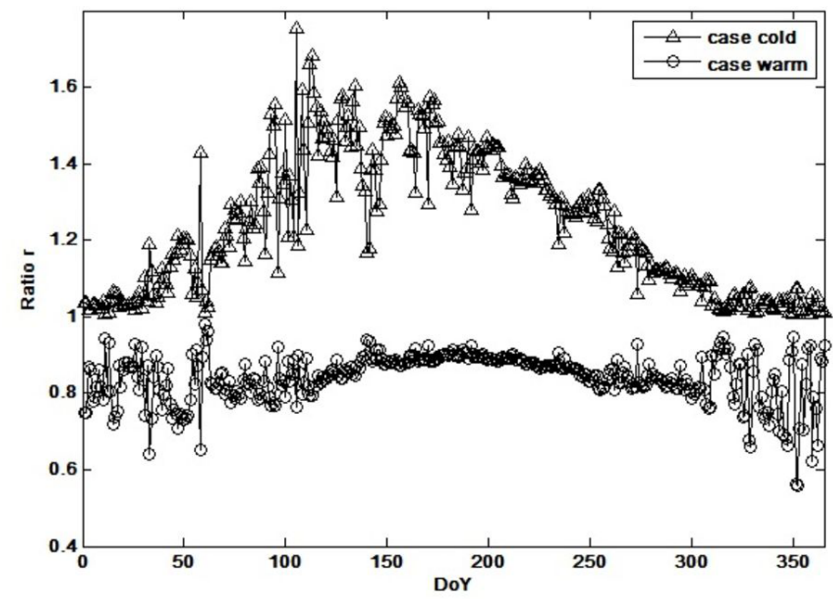

Fig. 8. Black circles: ratios $r$ of LST case C to LST case A. Black triangles: ratios $r$ of LST case C to LST case B. LST for cases A, B and $\mathrm{C}$ shown in Fig. 6 .

as reference case $\mathrm{B}$ and calculate the ratio of cases $\mathrm{C}$ to case B we obtain the $r(t)$ "case cold" in Fig. 8. We can now estimate the $\operatorname{LST}(t)$ of case C using either case A as reference and the $r(t)$ "case warm" or case B as reference and the $r(t)$ "case cold", obtaining in both cases exactly the same LST $(t)$ of case C. As an example let us take DoY 200 when LST is $43.64^{\circ} \mathrm{C}$ for case A and $26.90^{\circ} \mathrm{C}$ for case B. The corresponding values of $r$ are 0.8891 with A as reference and 1.4424 with B as reference. The estimated value of LST for case $\mathrm{C}$ is $38.80^{\circ} \mathrm{C}$ in both cases. This shows that the choice of the reference case is arbitrary and different choices lead to different values of $r(t)$, but all choices lead to the same $\operatorname{LST}(t)$.

Such relation between the shape of $r(t)$ and known properties can be used for the interpretation of the observed $r(t)$ obtained from the analysis of the MODIS LST time series, as shown below using the entire set of the 24 case.

We calculated first the ratio $r$ (Fig. 8) by choosing as reference the warmest one of our 24 cases, since our reference location (see Fig. 2) had higher LST in the study area. When using all combinations of the parameters values in Table 8 (Fig. 9: all cases) the estimated range of variability for all 24 cases is much larger than the observed variability of $r$ 
Table 8. Values of the parameters applied to construct a synthetic sample of LST time series by using Eqs. (8)-(13).

\begin{tabular}{lll}
\hline Variable & Values & Unit \\
\hline$\phi_{\mathrm{a}}$ & $0.09 ; 0.35$ & $\mathrm{rad}$ \\
$\phi_{n}$ & $0 ; \pi$ & $\mathrm{rad}$ \\
$\alpha$ & forest $=0.15$; pasture $=0.25$; bare soil $=0.35$ & Dimensionless \\
$G / \mathrm{Rn}$ & forest $=0.1$; pasture $=0.2 ;$ bare soil $=0.3$ & Dimensionless \\
$\lambda$ & dry sand $=0.2$; wet sand $=1.7$ & $\mathrm{~W} \mathrm{~m}^{-1} \mathrm{~K}^{-1}$ \\
$\rho \cdot \mathrm{C}$ & dry sand $=0.96 \times 10^{\wedge} 6$; wet sand $=3 \times 10^{\wedge} 7$ & $\mathrm{~J} \mathrm{~K}^{-1} \mathrm{~m}^{-3}$ \\
\hline
\end{tabular}

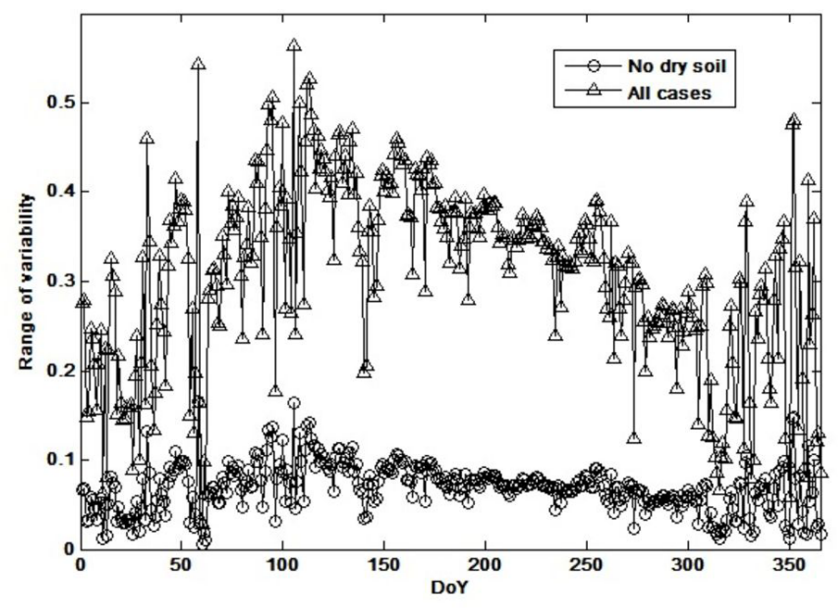

Fig. 9. Daily values of the range of variability of the ratio $r$ for all cases (open triangles) calculated using equation 8 and the parameter values in Table 8 , respectively, leaving out the 12 cases calculated with the dry soil thermal admittance (open circles).

(Fig. 4) both in summer and winter. Conversely when leaving out all cases for the perfectly dry soil (Fig. 9: no dry soil), the observed and estimated variability (over the remaining 12 cases) are comparable. This suggests that no location in the study area corresponds with the "perfectly dry soil" case.

\subsection{Accuracy of estimated air temperature}

To determine the accuracy and, possibly, to identify the weaknesses of our method we proceeded in two different ways:

Test 1: We used the ratio $r(x, y, t)$ calculated from the mean values of Fourier coefficients from 2000 to 2006 to calculate the air temperature in the successive years (2007-2009), when $T_{\mathrm{a}}$ data at the four stations (Telese, Solopaca, Castelvenere and Guardia Sanframondi) were available.

Test 2: We used a set of data collected during the preMODIS period of time at ground stations within the MODIS image frame. Some of these stations are located outside the Valle Telesina area, although in the same physiographic region. These data were rather sparse both in time and in space because of the irregular operation of the stations.
Table 9. Statistics of the test 1 (values in K). Error statistics of $T_{\mathrm{a}}$ estimates over 2007 to 2009 using the mean of the Fourier coefficients from 2000 to 2006 against $T_{\mathrm{a}}$ observations.

\begin{tabular}{lrrrrr}
\hline & \multicolumn{5}{c}{ TEST 1 } \\
\cline { 2 - 6 } & RMSE & AME & MR & STDR & $R^{2}$ \\
\hline Castelvenere & 3.33 & 2.81 & 2.25 & 2.45 & 0.94 \\
Telese & 2.41 & 1.88 & 0.80 & 2.27 & 0.95 \\
Guardia Sanframondi & 3.30 & 2.78 & -0.25 & 3.29 & 0.90 \\
Solopaca & 1.98 & 1.55 & -0.20 & 1.97 & 0.95 \\
\hline
\end{tabular}

In each test we compared estimated maximum daily $T_{\mathrm{a}}$ with the one measured at the available ground stations.

Table 9 shows the statistics of the test 1 . RMSE values range between 1.98 and $3.33 \mathrm{~K}$. Higher values were found for the Castelvenere and Guardia Sanframondi stations, although the mean deviation for Guardia is rather small, i.e. $-0.25 \mathrm{~K}$. The RMSE values for all the stations are consistent with the literature reviewed in the Introduction (e.g. Yan et al., 2009; Shen and Leptoukh, 2011). The results of Test 2 (Table 10) are less clear-cut: overall we have overestimated $T_{\mathrm{a}}$, particularly during the winter, but the available observations span a very short period of time. For all stations shown in Table 10 observations are available for just about one year, even in different years. Larger errors were observed for stations located at higher altitude, i.e. $523 \mathrm{~m}$ at Piedimonte Matese and $865 \mathrm{~m}$ at Piedimonte Matese Muto (see Fig. 2). The RMSE values found when using the same linear regression relationship for the entire area were slightly larger than when using station specific relationships (Table 6). We have observed that both slope and intercept depend on elevation but it was not possible to parameterize such dependence on elevation with sufficient accuracy given the limited number of stations at higher elevation and the short record of observations. To some extent the difference between estimated and observed daily $T_{\mathrm{a}}$ is due to the quality of observations. We have evaluated the data records for all available stations and noted in several cases that the observations are affected by significant noise, i.e. large and sudden deviations from the trend over a short period of time. To assess this effect we have applied a five-day moving average filter to observed $T_{\mathrm{a}}$ and evaluated the standard deviation over the five-day window (Fig. 10). We also noted in some cases large and inconsistent differences between stations (not shown here), suggesting significant impact of changes in the instruments used. We conclude that the RMSE values we obtained for our daily $T_{\mathrm{a}}$ estimates is due to a significant extent to noisy daily station data and we have, therefore, evaluated five-day averages of our estimates against five-day averages of $T_{\mathrm{a}}$ observations (Table 11). The accuracy of our estimates is significantly better, while a systematic assessment of observed $T_{\mathrm{a}}$ will require a separate study. 
Table 10. Statistics of the Test 2 (values in K). Error statistics of $T_{\mathrm{a}}$ estimates in different periods of time using the mean of the Fourier coefficients from 2001 to 2011.

\begin{tabular}{lrrrrr}
\hline & \multicolumn{5}{c}{ TEST 2 } \\
\cline { 2 - 6 } & RMSE & AME & MR & STDR & $R^{2}$ \\
\hline Castelvenere (1999-2000) & 2.86 & 2.27 & 1.48 & 2.45 & 0.94 \\
Solopaca (1999) & 2.74 & 2.13 & 0.09 & 2.74 & 0.90 \\
Bucciano (1984) & 3.11 & 2.57 & 2.31 & 2.09 & 0.95 \\
Piedimonte Matese (1984-1985) & 4.9 & 3.93 & 3.03 & 3.85 & 0.92 \\
Piedimonte Matese M. (1984-1985) & 4.64 & 3.72 & 2.84 & 3.67 & 0.95 \\
\hline
\end{tabular}

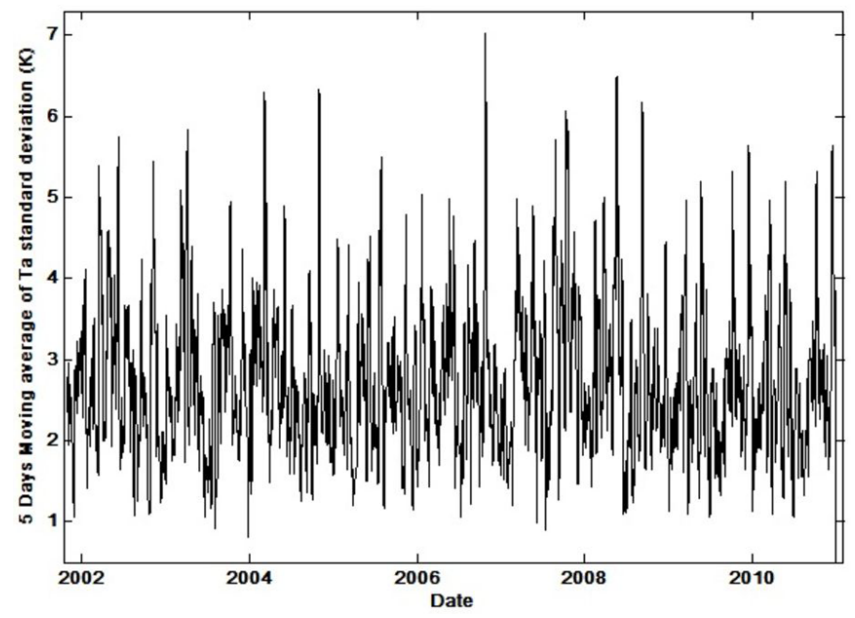

Fig. 10. Five-day moving average standard deviation of observed $T_{\mathrm{a}}$ at Guardia Sanframondi station.

\section{Conclusions}

We presented a new approach to map air temperature at high resolution. The innovation is in the use of time series of land surface temperature (LST) observed by a spaceborne imaging radiometer to construct a stable model of the spatial and annual pattern of LST and, subsequently, to estimate time series of air temperature $T_{\mathrm{a}}$ maps using such model. The spatial and annual pattern of LST is constructed by normalizing the LST $(x, y, t)$ at any location to the LST $\left(x_{0}, y_{0}, t\right)$ at a reference location $\left(x_{0}, y_{0}\right)$. In our study the latter is a node where gridded climate data are available for both past and future climate. Once the model $r(x, y, t)$ has been constructed we estimate $T_{\mathrm{a}}(x, y, t)$ using only the $T_{\mathrm{a}}\left(x_{0}, y_{0}, t\right)$ at the reference location. The relationship between $T_{\mathrm{a}}$ and LST has been constructed using a limited number (just four in this study) of meteorological stations. This is inherently different from approaches reported in literature where air temperature is estimated from concurrent observations of LST or LST and NDVI. The advantage of our method is that it can be applied to periods of time, including predicted future climate, when no LST observations are available. The accuracy of our estimates daily $T_{\mathrm{a}}$ is comparable, e.g. RMSE $\cong 3 \mathrm{~K}$, with other studies, which are based on using concurrent satellite data.
Table 11. Test 1 and Test 2 RMSE and AME statististics using fiveday mean $T_{\mathrm{a}}$ (values in $\mathrm{K}$ ).

\begin{tabular}{lrrrrrr}
\hline & \multicolumn{2}{c}{ TEST 1 } & & \multicolumn{2}{c}{ TEST 2 } \\
\cline { 2 - 3 } \cline { 5 - 6 } & RMSE & AME & & RMSE & AME \\
\hline Castelvenere & 2.87 & 2.31 & & 2.36 & 1.37 \\
Telese & 2.03 & 1.58 & & & \\
Guardia Sanframondi & 3.02 & 2.67 & & & \\
Solopaca & 1.58 & 1.27 & & 1.96 & 1.52 \\
Bucciano & & & & 2.66 & 2.29 \\
Piedimonte Matese & & & & 4.5 & 3.53 \\
Piedimonte Matese M. & & & & 4.41 & 3.49 \\
\hline
\end{tabular}

We obtained comparable error statistics when applying our method to LST data during periods different but adjacent to the periods used to construct the model of spatio-temporal variability of LST i.e. using only the $T_{\mathrm{a}}\left(x_{0}, y_{0}, t\right)$ at the reference location. When applying the same model to periods of time in the past (1984-1988) when some $T_{\mathrm{a}}$ observations were available for very short periods of time at a few meteorological stations, we obtained in some cases slightly larger error of estimates. The larger deviations were observed for two stations located at higher elevation where just two years of observations were available. Although this may suggest a dependence of the regression coefficients on elevation, the number and distribution of stations is not sufficient to determine a relationship between regression coefficients and elevation. There might be other multiple causes for such larger errors, including changes in the location of the concerned meteorological stations (documented by different coordinates available on record for such stations) and changes in land cover, which would lead to a different relationship between LST and $T_{\mathrm{a}}$. We have observed that the variability of $T_{\mathrm{a}}$ at the available meteo-stations over a five-day window suggests a significant random noise in the station data. This has a significant impact on the error statistics for daily estimates and we have obtained a smaller RMSE when evaluating five-day averages of estimated vs. observed $T_{\mathrm{a}}$. We have also shown that the spatial annual pattern of LST has a rather limited inter-annual variability, i.e. the pattern is mainly determined by the combination of the yearly evolution of solar irradiance with rather stable landscape properties such terrain, land cover (albedo, aerodynamic roughness) and soil thermal properties.

Acknowledgements. The work was carried out within the Italian national project AGROSCENARI funded by the Ministry for Agricultural, Food and Forest Policies (MIPAAF, D.M. $8608 / 7303 / 2008$ ). We are grateful to one anonymous reviewer who provided detailed comments which contributed very significantly to improve our manuscript.

Edited by: G. Petropoulos

Reviewed by: two anonymous referees 


\section{References}

Alfieri, S. M., De Lorenzi, F., Bonfante, A., Basile, A., and Menenti, M.: Mapping air temperature by Fourier analysis of land surface temperature time series observed by TERRA/MODIS, in: Proceedings of the 1st EARSeL Workshop on Temporal Analysis of Satellite Images, Mykonos, Greece, 21-24 May 2012, 34-43, 2012

Allen, R. G., Trezza, R., and Tasumi, M.: Analytical integrated functions for daily solar radiation on slopes, Agr. Forest Meteorol., 139, 55-73, 2006.

Bertoldi, G., Notarnicola, C., Leitininger, G., Endrizzi, S., Zebish, M., Della Chiesa, S., and Tappeiner, U.: Topographical and ecoidrological controls on land surface temperature in an aline catchment, Ecoidrology, 3, 189-204, 2010.

Cresswell, M. P., Morse, A. P., Thomson, M. C., and Connor, S. J.: Estimating surface air temperatures, from Meteosat land surface temperatures, using an empirical solar zenith angle model, Int. J. Remote Sens., 20, 1125-1132, 1999.

Czajkowski, K. P., Mulhern, T., Goward, S. N., Cihlar, J., Dubayah, R. O., and Prince, S. D.: Biospheric environmental monitoring at BOREAS with AVHR, J. Geophys. Res. Atmos., 102, 651-662, 1997.

Czajkowski, K. P., Goward, S. N., Stadler, S. J., and Walz, A., Thermal remote sensing of near surface environmental variables: Application over the Oklahoma Mesonet, Professional Geogr., 52, 345-357, 2000

Dobrowski, S. Z., Abatzogloub, J. T., Greenbergc, J. A., and Schladowd, S. J.: How much influence does landscape-scale physiography have on air temperature in a mountain environment?, Agr. Forest Meteorol., 149, 1751-1758, 2009.

Esposito, S.: Prime Caratterizzazioni agro-climatiche delle aree di studio di Agroscenari mediante i dati dei nodi di griglia, Technical Note, Agroscenari, CRA-CMA, Rome, Italy, 30 pp., 2010.

Hengl, T., Geuvelink, G. B. M., and Stein, A.: Comparison of Kriging with external drift and regression kriging, ITC technical note, available at: http://www.itc.nl/Pub/Home/library (last access: 4 July 2013), 2003.

Hengl, T., Heuvelink, G. B. M., Perčec Tadić, M., and Pebesma, E. J.: Spatio-temporal prediction of daily temperatures using timeseries of MODIS LST images, Theor. Appl. Climatol., 107, 265277,2012

Gallo, K., Hale, R., Tarpley, D., and Yu, Y.: Evaluation of the Relationship between Air Temperature and Land Surface Temperature under Clear- and Cloudy-Sky Condition, J. Appl. Meteorol. Climatol., 50, 767-775, 2011.

Gao, F., Morisette, J. T., Wolfe, R. E., Ederer G., Pedelty, J., Masuoka, E., Myneni, R., Tan, B., and Nightingale, J.: An Algorithm to Produce Temporally and Spatially Continuous MODIS-LAI Time Series, Geosci. Remote Sens. Lett., 5, 60-64, doi:10.1109/LGRS.2007.907971, 2008.

Goward, S. N., Waring, R. H., Dye, D. G., and Yang, J. L., Ecological remote-sensing at OTTER - Satellite macroscale observations, Ecol. Appl., 4, 322-343, 1994.

Gu, L., Meyers, T., Pallardy, S. G., Hanson, P., Yang, B., Heuer, M., Hosman K. P., Riggs, J. S., Sluss, D., and Wullschleger, S. D: Direct and indirect effects of atmospheric conditions and soil moisture on surface energy partitioning revealed by a prolonged drought at a temperate forest site, J. Geophys. Res., 111, D16102, doi:10.1029/2006JD007161, 2006.
Jones, P., Jedlovec, G., Suggs, R., and Haines, S.: Using MODIS LST to estimate minimum air temperature at night, in: 13th Conference on Satellite Metereology and Oceanography, American Metereological Society, Norfolk, Virginia, 6 pp., 2004.

Julien, Y., Sobrino, J., and Verhoef, W.: Changes in land surface temperatures and NDVI values over Europe between 1982 and 1999, Remote Sens. Environ., 103, 43-55, 2006.

Kawashima, S., Ishida, T., and Miwa, T.: Relations between Surface Temperature and Air Temperature on a Local Scale during Winter Nights, J. Appl. Metereol., 39, 1570-1579, 2000.

Kustas, W. P., Daughtry, C. S. T., and Van Oeven, P. J.: Analytical Treatment of the Relationships between Soil Heat Flux/Net Radiation Ratio and Vegetation Indices, Remote Sens. Environ., 46, 319-330, 1993.

Mahmood, R., Foster, S., Keeling, T., Hubbard, K., Carlson, C., and Leeper, R.: Impacts of irrigation on 20th century temperature in the northern Great Plains, Global Planet. Change, 54, 1-18, 2006.

Menenti, M.: Physical Aspects and Determination of Evaporation in Deserts Applying Remote Sensing Techniques Wageningen, The Netherlands: Institute for Land and Water Management Research, Report 10, 1984.

Menenti, M., Azzali, S., Verhoef, W., and Van Swol, R.: Mapping agroecological zones and time lag in vegetation growth by means of Fourier analysis of time series of NDVI images, Adv. Space Res., 13, 233-237, 1993.

Menenti, M., Jia L., Azzali, S., Roerink G., Gonzalez-Loyarte M., Leguizamon S., and Verhoef W.: Chapter 6 (Analysis of vegetation response to climate variability using extended time series of multispectral satellite images) in: Remote Sensing Optical Observation of Vegetation Properties, edited by: Maselli, F., Menenti, M., and Brivio, P. A., Research Signpost, Trivandrum (IND), 131-164, 2010.

Ministero dell'Agricoltura e delle Foreste - Sistema informativo Agricolo Nazionale, Ufficio Centrale di Ecologia Agraria, 1990 - "Analisi climatologica e progettazione della rete agrometereologica Nazionale. Nord Italia, Puglia e Sicilia" Ministero dell'agricoltura e dlle foreste (MAF), Roma, 1-97, 1990.

Mostovoy, G., King, R., Reddy, K., Kakani, V., and Filippova, M.: Statistical estimation of daily maximum and minimum air temperatures from MODIS LST over the State of Mississipi, GIScience Remote Sens., 43, 78-110, 2006.

Nemani, R. R. and Running, S. W.: Land cover characterization using multitemporal red, near-IR, and thermal-IR data from NOAA/AVHRR, Ecol. Appl., 7, 79-90, 1997.

Nieto, H., Sandholt, I., Aguado, I., Chuvieco, E., and Stisen, S.: Air temperature estimation with MSG-SEVIRI data: Calibration and validation of the TVX algorithm for the Iberian Penisula, Remote Sens. Environ., 115, 107-116, 2011.

Oke, T. R.: Boundary Layer Climates, 2nd Edn., New York, NY, Methuen, 345 pp., 1987.

Park, S., Feddema, J. J., and Egbert, S. L.: MODIS Land Surface Temperature Composite Data and Their Relationship with Climatic Water Budget Factos in Central Great Plains, Int. J. Remote Sens., 26, 1127-1144, 2005.

Prihodko, L. and Goward, S. N.: Estimation of Air Temperature from Remotely Sensed Surface Observations, Remote Sens. Environ., 60, 335-346, 1997. 
Roerink, G. and Menenti, M.: Reconstructing cloudfree NDVI composites using Fourier analysis of time series, Int. J. Remote Sens., 21, 1911-1917, 2000.

Shen, S. and Leptoukh, G. G.: Estimation of surface air temperature over central and eastern Eurasia from MODIS land surface temperature, Environ. Res. Lett., 6, 045206, doi:10.1088/17489326/6/4/045206, 2011.

Stisen, S., Sanholt, I., Norgaard, A., Fensholt, R., and Eklundh, L.: Estimation of diurnal air temperature using MSG SEVORI data in West Africa, Remote Sens. Environ., 110, 262-274, 2007.

Tomozeiu, R., Cacciamani, C., Pavan, V., Morgillo, A., and Busuiocin, A.: Climate change scenarios for surface temperature in Emilia-Romagna (Italy) obtained using statistical downscaling models, Theor. Appl. Climatol., 90, 25-47, 2007.

Vacutsem, C., Ceccato, P., Dinku, T., and Connor, S. J.: Evaluation of MODIS land surface temperature data to estimate air temperature in different ecosystems over Africa, Remote Sens. Environ., 114, 449-465, 2010.

Verhoef, W., Menenti, M., and Azzali, S.: A colour composite of NOAA-AVHRR-NDVI based on time series analysis (19811992), Int. J. Remote Sens., 17, 231-235, 1996.
Vogt, J. V., Viau, A. A., and Paquet, F.: Mapping regional air temperature fields using satellite-derived surface skin temperatures, Int/ J. Climatol., 17, 1559-1579, 1997.

Wackernagel, H.: Multivariate Geostatistics: an introsuction with applications, 2nd Edn., Springer Verlag, 1998.

Wan, Z.: New refinements and validation of the MODIS LandSurface Temperature/Emissivity product, Remote Sens. Environ., 112, 59-74, 2008.

Wan, Z. and Dozier, J.: A generalized split-window algorithm for retrieving land-surface temperature from space, Trans. Geosci Remote Sens., 34, 892-905, 1996.

Wan, Z., Zhang, Y., and Zhang, Q.: Quality assessment and validation of the MODIS global land surface temperature, Int. J. Remote Sens., 25, 261-274, 2004.

$\mathrm{Xu}$, Y., Qin, Z., and Shen, Y.: Study on the estimation of nearsurface air temperature from MODIS data by statistical methods, Int. J. Remote Sens., 33, 7629-7643, 2012.

Yan, H., Zhang, J., Hou, J., and Hea, J.: Estimation of air temperature from MODIS data in east China, Int. J. Remote Sens., 30, 6261-6275, doi:10.1080/01431160902842375, 2009.

Yonghui, Y. and Baiping, Z.: MODIS-based air temperature estimation in the southeastern Tibetan Plateau and neighboring areas, J. Geogr. Sci., 22, 152-166, 2012. 